\title{
Engaging with rural patients and clinics to develop colorectal cancer screening messaging and outreach using adapted Boot Camp Translation
}

Jennifer Coury ( $\nabla$ coury@ohsu.edu )

Oregon Health \& Science University

Gloria Coronado

Kaiser Permanente Center for Health Research

Emily Myers

Oregon Health \& Science University

Mary Patzel

Oregon Health \& Science University

Jamie Thompson

Kaiser Permanente Center for Health Research

Melinda Davis

Oregon Health \& Science University

\section{Research Article}

Keywords: Colorectal cancer screening, rural health, patient outreach, patient engagement, Boot Camp Translation

Posted Date: February 25th, 2022

DOI: https://doi.org/10.21203/rs.3.rs-1340591/v1

License: (c) (i) This work is licensed under a Creative Commons Attribution 4.0 International License. Read Full License 


\section{Abstract \\ Background}

Colorectal cancer (CRC) incidence and mortality are disproportionately high among rural residents and Medicaid enrollees. Mailed fecal immunochemical testing (FIT) can raise screening rates, but rural patients have lower response rates than their urban counterparts. To help address these persistent disparities, we tailored mailed FIT screening messages for rural, Medicaid enrollees using a patient engagement approach called Boot Camp Translation (BCT).

\section{Methods}

A modified BCT was conducted with eligible patients (English-speaking and ages 50 to 74) and clinic staff involved in patient outreach, and located in rural areas. To accommodate COVID-related restrictions, BCT was conducted virtually. In four sessions held over two months, participants learned about CRC and considered messaging and outreach. We used rapid turn-around qualitative methods to analyze recordings of the sessions and the detailed field notes.

\section{Results}

Thirteen adults agreed to participate in BCT; however, six could not engage due to COVID-related difficulties (4) or other reasons (2). Several key areas emerged that reflected messaging tailored for rural populations, such as being direct about cancer, close clinic-patient connections, and not including family pictures. Other themes were CRC seriousness, test safety and ease, and the low cost of FIT. The recommended outreach approach included a live phone call prior to the mailing, sharing a CRC information sheet, and text or phone reminders a week after the FIT mailing.

\section{Conclusions}

We were able to successfully use remote methods to gather rural patient feedback about a mailed FIT outreach program and CRC screening messages. We used this information to adapt mailed FIT materials including introduction (or prompt) letter, a letter to accompany the mailed FIT, phone scripts, and best practices recommendations. By finding themes and modalities that are preferred by a rural population, we hope to inform others working across the country with this hard-to-engage, yet underserved, population.

\section{Background}

Colorectal cancer (CRC) screening is a highly effective evidence-based practice, (1) but disparities persist between populations receiving screening. Rural residents are less likely than their urban counterparts to be current on screening, which leads to higher incidence and mortality from the disease.(2-5) Rural areas 
are home to about 60 million people in the United States or about $20 \%$ of the population. (4) Key barriers to CRC screening among rural patients are high cost, lack of time, fear of burdening family, lack of privacy, and transportation.(6) Medicaid enrollees are a key underserved group in rural areas (7) with relatively low rates of CRC screening: in national data from 2018 54\% for Medicaid vs. $65 \%$ for commercially insured people and $73 \%$ of Medicare-insured people were up to date with CRC screening recommendations. $(8,9)$ Medicaid members also display worse CRC outcomes than commercially insured adults. $(10,11)$

Mailing fecal immunochemical test (FIT) kits directly to patients is increasingly recognized as an effective population outreach intervention to minimize patient barriers(12) and improve CRC screening rates.(13-16) In addition, screening rates improve with an informational letter prior to FIT mailing,(17) patient reminders (such as phone calls),(17) tailoring outreach messaging, $(12,17)$ and pre-addressed stamped envelopes for FIT returns. While visit-based strategies such as in-clinic FIT distribution improve screening rates in rural and low-income populations(18), the COVID-19 pandemic has made screening that does not require a visit to a health care facility even more crucial. $(19,20)$

Although mailed FIT is effective, rural populations experience disparities in response to mailed FIT compared to their urban counterparts. In a centralized mailed FIT outreach program delivered to 8,551 Washington state Medicaid enrollees, rural FIT completion rates were $16 \%$, compared to $19 \%$ in urban enrollees $(p=.05)$. (21) Lower response rates in rural populations may be due in part to lower baseline screening rates, limited awareness of FIT as a CRC screening option, or cultural difference in responsiveness to population outreach programs. Research is needed to explore how to optimize screening in rural populations, a need amplified due to COVID impacts on CRC screening disparities. According to new Uniform Data System (UDS) data,(22) CRC screening rates in Federally Qualified Health Centers dropped from 45\% in 2019 to $40 \%$ in 2020 nationally, and the National Cancer Institute has recommended increased remote testing to decrease pandemic-related disparities.(23)

Patient and community engagement are important strategies for adapting effective intervention programs and tailoring outreach messages to priority populations. One way to refine mailed FIT materials for rural populations is by using a participatory approach called Boot Camp Translation (BCT). BCT is an iterative process that prioritizes locally relevant and culturally appropriate language to make scientific evidence-based guidelines more accessible for patients and community members.(24) Members of our study team have used a modified version of this approach successfully with an urban Latino population in California to explore messaging and refine FIT materials and mailing steps. $(25,26)$

Therefore, we used a modified BCT process designed to answer the following three research questions: 1. What should we emphasize in our colorectal cancer screening messages to rural unscreened patients as part of a mailed FIT program with follow-up colonoscopy? 2. What is the best way to deliver outreach alerts or reminders to rural unscreened patients as part of a mailed FIT program? and 3 . What do patients need to hear or see to encourage colon cancer screening in light of COVID-19? This manuscript describes the BCT process adapted for the COVID-19 context and summarizes the BCT findings. 


\section{Methods}

Our study, Screening More Patients for Colorectal Cancer through Adapting and Refining Targeted Evidence-based Interventions in Rural Settings (SMARTER CRC) (ClinicalTrials.gov \#: NCT04890054), was designed to reduce disparities in CRC screening, follow-up, and referral to care for rural Medicaid patients. SMARTER CRC uses a mailed FIT and patient navigation program to support follow-up colonoscopy after abnormal FIT. An Advisory Board includes members representing clinic, health plan, researcher, policy, and patient perspectives to help guide the study. We used a modified BCT process to adapt the mailed FIT program materials (e.g., introductory letter, mailing letter, information sheet, phone scripts) to rural settings and to define mailing and reminder components for the SMARTER CRC intervention. BCT activities were deemed non-human subjects research by the Oregon Health \& Science University (OHSU) Institutional Review Board (IRB \# STUDY00020681).

\section{Recruitment}

BCT participants were rural patients and clinic staff. Participant recruitment occurred between April 2020June 2020.

Clinic Staff. Clinic staff from four SMARTER CRC pilot clinics were invited to take part in the BCT sessions; these clinics were rural or frontier according to Rural-Urban Commuting Area codes(27) and the Oregon Office of Rural Health Designation,(28) had a lower than 60\% CRC screening rate, and care for Medicaid patients. We also worked with these four pilot clinics to refine the patient inclusion criteria and recruitment approach for BCT.

Patients. Patients eligible for BCT were English speaking men or women ages 50-74 without a personal history of CRC or colon disease, and able to participate in two online sessions and three phone calls over a 2-month period. We originally proposed to use research staff to outreach to patients, however, all participating clinics preferred to identify and outreach to patients directly using clinic staff who have personal and trusted connections with the patient population. Two of the four participating clinics recruited participants by sharing patient-facing fliers created by the research team. Due to competing priorities with COVID-19 at these clinics, we expanded our patient recruitment efforts by asking our 12member Advisory Board to distribute fliers to rural patients meeting eligibility criteria.

\section{BCT Intervention}

BCT has been used to gain community input on a wide range of health topics such as diabetes, biobanks, cancer screening, and asthma diagnosis. $(29,30)$ As summarized in Table 1, prior work by our team adapted BCT for rapid input on cancer screening interventions in an urban Latino population. $(25,26)$ We had planned to use this modified BCT approach, which included remote sessions plus a condensed oneday in-person session. While this abbreviated format would accommodate rural-based participants needing to travel, we would have needed to limit participation to a single regional area to make it more feasible. Ultimately, we had to shift to accommodate COVID-19 related mandates (i.e., restricted non- 
essential travel and safety). Therefore, we further refined our approach to fully virtual delivery as described below. Key changes are detailed in Table 1.

Table 1

Adaptations Made to the Boot Camp Translation Process for COVID-19 Context

\begin{tabular}{|c|c|c|c|}
\hline Component & $\begin{array}{l}\text { Prior Modified BCT } \\
\text { (PROMPT study) }\end{array}$ & $\begin{array}{l}\text { SMARTER CRC Planned Rural } \\
\text { Approach }\end{array}$ & $\begin{array}{l}\text { SMARTER CRC COVID-19 } \\
\text { Adapted Approach }\end{array}$ \\
\hline $\begin{array}{l}\text { Eligibility } \\
\text { Criteria }\end{array}$ & $\begin{array}{l}\text { (a) Latino, (b) age- } \\
\text { eligible for CRC } \\
\text { screening, (c) able } \\
\text { to speak English or } \\
\text { Spanish (d) able to } \\
\text { participate in in- } \\
\text { person meeting } \\
\text { and phone calls }\end{array}$ & $\begin{array}{l}\text { (a) enrolled in Medicaid, other } \\
\text { types of health insurance, or } \\
\text { uninsured, (b) eligible for CRC } \\
\text { screening, (c) reside in a rural } \\
\text { community, (d) assigned to } \\
\text { the clinic by partner CCO, and } \\
\text { (e) able to speak English or } \\
\text { Spanish }\end{array}$ & $\begin{array}{l}\text { (a) enrolled in Medicaid, other } \\
\text { types of health insurance, or } \\
\text { uninsured (b) eligible for CRC } \\
\text { screening, (c) reside in a rural } \\
\text { community, (d) able to speak } \\
\text { English, (e) access to Wi-Fi by } \\
\text { going to the clinic or at home }\end{array}$ \\
\hline Format & $\begin{array}{l}\text { Iterative meetings: } \\
\text { One 6-hour in- } \\
\text { person day } \\
\text { followed by three } \\
\text { conference calls } \\
\text { over a 3-month } \\
\text { period. }\end{array}$ & $\begin{array}{l}\text { Iterative meetings: One 6-hour } \\
\text { in-person day (allowing for } \\
\text { travel time), in a location close } \\
\text { to one of the pilot clinics, } \\
\text { followed by two conference } \\
\text { calls and one final in-person } \\
\text { meeting. }\end{array}$ & $\begin{array}{l}\text { One } 30 \text {-minute } 1: 1 \text { meet and } \\
\text { greet intake call with each } \\
\text { participant, one } 3 \text {-hour group } \\
\text { video call, two } 30 \text { - minute } \\
\text { video calls, and one final one- } \\
\text { hour video call over a } 2- \\
\text { month period. }\end{array}$ \\
\hline
\end{tabular}

One-to-two weeks prior to the first BCT session (May 2020), all patient participants were called for a meet and greet by a member of the study team (EM). The purpose of the phone call was to welcome the participant and build initial rapport, confirm their mailing address, assess their technology access, and coach them to ensure they could join at least one video call. Additionally, a short participant demographic survey was conducted over the phone. After the phone call, each participant received Zoom meeting information via email. To improve engagement, each participant was mailed a BCT care package prior to the first session which included Zoom instructions, meeting materials including a sample letter and FIT, a poop emoji ballpoint pen, snacks, and a thank you card.

After the initial intake call, four BCT sessions were held over a 2-month period between June-August 2020, participants learned about CRC and considered the best messaging, approach, and reminders to encourage FIT completion. All BCT sessions were conducted via Zoom (as shown in Fig. 1), and participants could join the later sessions by phone if needed. Sessions lasted between thirty minutes to three hours. Participants were sent reminder emails before each session. Patient participants were sent incentives for each session they attended (\$150 for the first session, $\$ 25$ for the second session, $\$ 25$ for the third session, $\$ 50$ for the last session). Incentives were mailed out with a thank you card after the final session.

BCT sessions were facilitated by a lead (JC) and co-lead (MMD) throughout all four sessions. The team also had one consistent administrative support person, who monitored the chat box and asked questions (EM). Study team members also asked questions of the facilitators, so that participants became more comfortable sharing out ideas and asking questions. One key expert (GC) presented during the first three- 
hour session. All sessions were recorded, saved for analysis, and transcribed. The research team used the BCT sessions to collaboratively create mailed FIT materials by summarizing the messages we were hearing and reviewing updated versions of the mailing materials in the latter BCT sessions.

\section{Qualitative Methods}

One qualitative analyst (MP), present during all four sessions, observed the sessions and took detailed field notes. We conducted a rapid analysis of our detailed field notes in alignment with "rapid turnaround" methods, $(31,32)$ and captured quotes from the recordings. Findings (i.e., field notes and transcripts) were analyzed at the end of all sessions. First, the field notes from each BCT session were reviewed one by one to create neutral domain names (following the method described by Hamilton et al) (32) that correspond to our key BCT questions. Second, after each set of field notes were reviewed, the neutral domains were compiled and consolidated into a summary template. Third, all fieldnotes were rereviewed and the key findings were documented under the appropriate domain in the summary template. For the purposes of our work, we did not transfer the summary of our findings into a matrix to separate out respondents by domain to protect participant privacy. As a final analytic step, we looked across the themes and domains from each session to determine overall findings.

\section{Results}

Our findings reflect the answers to the three key questions that guided the BCT: what to emphasize in messages; what is the best way to deliver outreach; and what would encourage CRC screening in light of COVID-19. We present the messages suggested during BCT, identified barriers to screening, and the cocreated mailed FIT materials and overall mailing protocol produced by the BCT process.

\section{Participant Characteristics}

Thirteen adults agreed to participate in BCT; however, four could not participate due to COVID-related difficulties and two did not participate for other reasons. The seven remaining participants (4 patients \& 3 clinic staff) had a range of health coverage types (private insurance, Medicaid/Medicare, and uninsured), were all female, and were Black and White individuals who lived in rural areas across the state of Oregon.

\section{Wording or Messages to Emphasize in CRC Screening Outreach}

Our BCT participants liked that mailed FIT was a less invasive CRC screening option for low-risk patients. BCT participants discussed barriers, what would encourage rural patients to return FITs, and who to target for outreach. Table 2 summarizes identified barriers that prevent CRC screening which range from stigma of CRC screening and fear of letting down family ("who is going to take care of my family?") to logistical barriers such as cost, transportation, or knowing how to return a completed FIT. 
Table 2

BCT Participant-Identified Barriers to Screening

\section{Themes Example Quotes}

Fear of letting "Say you are the breadwinner of the family and you have symptoms, but you're family down afraid to go because you may have CRC. You might think to yourself "who is going to take care of my family? That is a big fear of a lot of people in my area"

Lack of

"Some people don't have transportation to go to the doctor"

transportation

Invasiveness

"For me, it's more the process about the invasiveness of what a colonoscopy entails."

"Dollar factor":

Too many Bills or

Unconventional

insurance

"My biggest reason for not getting screened is the cost, because I don't have conventional insurance. And I need to pay my bills. And that's to me, that is more important than life...but is it? Nobody wants phone calls that you're behind on your bills."

Some patients don't/can't read

"I advocated for myself. And a lot of my patients, they don't know. And I work, I'll go to bat for them and I'll fight for them. One of my patients, he doesn't read. And we opened the box and we read through it."

How to return the FIT

[FITs can be mailed from home] "might be a stress point, so they know they don't have to go back out into town"

They like having multiple return options (drop off at post office, etc.).

Stigma

"I think there's a big stigma about it. But that's what this is about, trying to work around that. I do think they feel funny about it."

A majority of the BCT sessions focused on how we should tailor messages about mailed FIT and COVID19 impacts. Consensus was reached on almost all preferred messages, which are described in Table 3. However, wording related to "time sensitive material," did not achieve consensus by the BCT participants. In addition, our study participants raised the issue of cost numerous times and reacted strongly to the topic, and commented on the perception of potential costs (even when the test was covered by insurance). 


\section{Themes/ Messages to Example Quotes}

\section{Emphasize}

Seriousness of CRC; second leading cause of death

Cost (how much out of pocket, if not covered by insurance)

Clinics cares ("Your health is important")

Ease of test

Privacy

"Call it what it is" - Avoid fancy language, be up front

Prevention-based messaging
"I was completely amazed that it's the second leading cause of [cancer] death. That pretty much blows me out of the water at this point."

"My biggest reason for not getting screened is the cost, because I don't have conventional insurance. And I need to pay my bills."

"If it's 25 dollars at worst, why are we not promoting that? Looking at a $\$ 500$ bill [for a test] or a colonoscopy it's $\$ 3000$...I can't do that."

“This isn't something to ignore or set aside, it's important, your provider cares about you, we care about you."

"This poop on a paper sounds pretty simple to me."

"You can take it in the safety and privacy of your own home. A lot of people have an issue with privacy, especially where I live, older people do have an issue with privacy."

"Are you hiding something you're ashamed of? We're trying to save your life, people! Maybe it does have to be a wake-up call."

"Hey, you know, let's think about this. If you found out something was wrong, you can prevent something from happening. How does that feel?"

"Something that you could take back to your community and put them at ease, that it's not as bad as it seems, matter of fact it [screening] could save their lives."

\section{Content Suggestions to Make the Materials More Clear \\ Example Quotes}

Tell people what to expect "How about everything you need will be mailed to you"

"Include phone number to call if patient has questions"

Return timing issues and postal service

"How long does it stay good, the test, the sample is it good for a day, good for a week. We have delays with our carriers."

Bold or highlight the date section on the bottle, so patients see it

"Be sure to write the date of the test on the bottle. Check that your name and birthdate are CORRECTLY printed on the bottle."

\section{COVID-Related Themes to Example Quotes Emphasize}


Themes/ Messages to Emphasize

"Pandemic proof"

\section{Example Quotes}

"People are so freaked out by COVID but they ignore this other disease that we have. Really it should be the other way around, almost."

During the discussion of messaging, both clinic staff and patients had questions about the terminology "unscreened" and "unestablished" patients. The research team had defined unscreened as "due for CRC screening", but participant definitions ranged from "never having been tested" to "see[ing] a problem and not taking care of it" or "don't know how to ask for the test, or not proactive enough to ask, or don't know what a FIT is." Similarly, BCT participants indicated that the term "unestablished" patients, meaning patients who were enrolled in a health plan but had not seen at a particular clinic, was confusing.

\section{Incorporating Participant Recommendations Into Messaging and Program Components}

The research team incorporated these themes and modality suggestions into both updated materials and phone call scripts, and an adapted mailed FIT program recommended for rural clinics. The outreach materials (i.e., letters before and with the FIT and phone scripts) were tailored to enhance response (see Fig. 2 as an example). For example, instead of putting the image of a family on the letters, participants suggested the word cancer with a red line through it (i.e., NO Cancer). BCT participants suggested that images of families could lead to feelings of exclusion. Our participants shared that family photos are challenging because "...what my family looks like is going to be different from everyone else." Our redesigned printed materials included the words "completely FREE" and the word "FREE" was included in even brief reminder phone scripts and sample text messages to reflect concerns about cost.

Finally, our participants also wanted messages to be explicit and straight to the point, one participant said:

"I understand that colons are a private area and [some individuals may say] I'm not going to discuss that with anybody...[but], I'm a farm kid and we call things by their names and it doesn't faze me. ... We're trying to save your life, people! Let's figure out how to get it across. ... I don't think colon cancer is a bad word. If that's the second leading cause of death guys, I think we need to stress that. Forget the word, let's get on this."

BCT participants shared several communication preferences in relation to prompts or reminder calls. Patient and clinic participants preferred live phone calls that emphasized the call was made on behalf of their provider. They also felt that text messages that alert them when "it's been ordered, it's been shipped, it's been delivered" would be helpful, similar to what's used during mail order delivery. If texting was an option, the group preferred to receive a text reminder to return the FIT before clinic staff made live phone call reminders. Participants noted a potential downside to text was that our target population (i.e., rural 
Medicaid) may not always receive texts or they may get charged for text messages. Therefore, our participants suggested that clinic staff ask patients for their preferred method of contact. Other important communication preferences included encouraging clinic staff to leverage personal connections and use "small talk" with patients and more "media" coverage for CRC screening, such as posters in clinics or articles in the local newspaper. Participants had mixed opinions on whether incentives or "swag" (such as gift cards or t-shirts) would encourage people to return their FIT. Ultimately, in the SMARTER CRC pragmatic trial, the team did not make a recommendation on whether clinics should or should not provide an incentive (even small gifts) to facilitate test return.

The final BCT-informed mailed FIT protocol for the SMARTER CRC trial included: an advance notification (prompt) live phone call from the clinic, including a page of CRC facts with the FIT mailing, and having reminders by text or phone about a week after the FIT is mailed. Participants' reactions to the modified materials and process was positive, such as in the illustrative quote, "I'm super excited. As I read through the letter, I can see all the little points that we had discussed, even though they were just minor you've incorporated it. It makes me tickled on my part to know that we made an impact on it and that you listened. Thank you."

\section{Discussion}

We used an adapted patient engagement approach called Boot Camp Translation (BCT) to tailor mailed FIT screening messages and materials for rural, Medicaid enrollees. Our approach to BCT was initially adapted for a rural environment and then further adapted to accommodate COVID-19 travel restrictions and hosted fully online (Zoom). Despite these adjustments, and participation challenges due to COVID exposures, we were able to use BCT in a remote format to capture opinions about mailed FIT messaging, barriers to screening for rural patients, and communication modality preferences. Our qualitative analysis identified barriers to completing CRC screening, key themes for messages, and COVID-specific language to support CRC screening completion. We used this information to adapt mailed FIT materials including introduction (or prompt) letter, a letter to accompany the mailed FIT, phone scripts, and best practices recommendations.

\section{Findings Related to Mailed FIT}

Many key themes from our study reflect areas mentioned in prior research, such as cost concerns, privacy, not knowing the seriousness of CRC, and ease of use for FIT. $(17,33)$ Some barriers to CRC screening were similar as well, such as fear, literacy, and invasiveness of colonoscopy. (33) However, many of the messages and themes were unique to rural populations. Cost, which has been shown to be a barrier to screening,(33) seemed to have a greater urgency in this population as it was raised in numerous answers. Therefore, as reflected in Fig. 2, our redesigned printed materials included the words "completely FREE." Other unique themes were an emphasis on perceived closer clinic-patient relationships in rural communities (reflected in both personalized outreach and message wording such as thanking the participants in the redesigned letters. Participants also discussed the idea that rural patients would prefer doctors to "tell it like it is," so printed materials included the word "CANCER" in an attention grabbing 
image and the seriousness of CRC in the first text paragraph. One area that was a direct contrast to prior work was the participants' reactions to pictures of families in the materials. Our prior work in an urban Latino population found family messaging and images to be important, (25) but our rural participants indicated having a family picture might alienate individuals who could not relate or didn't identify with the image used.

In terms of modality, our participants preferred live phone calls that emphasized the call was made on behalf of their provider rather than automated phone calls. Several themes emphasized building on a personal connection, which is consistent with previous findings about outreach messages. $(17,25)$ Participants stressed that the clinic staff know their patients particularly well in rural areas and could capitalize on that during outreach. While BCT participants preferred text reminders, they also acknowledged others in rural areas might have cost restrictions on text messaging. Finally, while the discussion of "unestablished" patients did not affect wording in patient-facing mailed FIT materials, it has implications for clear communications between research teams and health plan/clinic partners during implementation.

\section{Learnings and Recommendations Regarding COVID- Adapted BCT}

Despite study team concerns about the ability to generate robust program insight, we were able to implement BCT sessions and form a cohesive group using video conferencing. While the overall number of hours spent in sessions was lower than if we had held full day in-person sessions, we elicited responses from all participants and the participants were able to share how the issues affected them. The phone call before the first video session was an innovation to help facilitate remote BCT and seemed to build rapport. Participants indicated our revised materials really reflected the input they had shared throughout the virtual sessions. Our findings and others' (34-36) indicate that virtual meetings might offer a positive way to reach across geographically dispersed participants in future research.

\section{Limitations and Future Directions}

Our study has certain limitations. The BCT sessions had a small sample size, and participants experienced pandemic-related disruptions, such as staffing shortages in clinics which limited attendance. While we had fewer participants than originally planned, this small number gave the participants ample opportunity to contribute to the discussions. Ultimately, our sample included participants who were highly engaged and from many different areas of rural Oregon. However, our sample was limited to sites within the state of Oregon, which might not be generalizable to other rural areas. Our approach used an abbreviated BCT method, whereas the original BCT involved multiple in-person meetings in addition to calls and could be 6-12 months or longer.(24) Our prior research demonstrated the feasibility of conducting an abbreviated in-person BCT program.(26)

\section{Conclusions}


Despite these limitations, we were able to use BCT in a remote format to capture diverse patient and clinic staff opinions about mailed FIT messaging, barriers to screening for rural patients, and communication modality preferences. We identified several key themes, such as personal connection, taking responsibility for your health, and direct communications, which could improve engagement with rural populations and might have applicability beyond the health domain of colorectal cancer screening.

Our findings provide many opportunities for future research, including studies to explore how mailed FIT using these suggestions for both messaging and modality is received by rural populations. Given that the US Preventive Services Task Force recently lowered the screening initiation age from 50 to 45,(1) future research could explore if younger populations need similar or different messaging to rural residents. And future research could explore if these themes apply to messaging about other health behaviors. We will use findings from this study to test effectiveness of the materials produced and the feasibility of any process suggestions in the subsequent SMARTER CRC cluster-randomized pragmatic trial.

\section{Abbreviations}

CRC

colorectal cancer

FIT

fecal immunochemical testing

$\mathrm{BCT}$

Boot Camp Translation

UDS

Uniform Data System

SMARTER CRC

Screening More Patients for Colorectal Cancer through Adapting and Refining Targeted Evidence-based Interventions in Rural Settings

ORPRN

Oregon Rural Practice-Based Network

\section{Declarations}

\section{Ethic approval and consent to participate}

\section{All methods were carried out in accordance with relevant guidelines and regulations under Ethics} approval. All experimental protocols were approved by the Institutional Review Board at Oregon Health \& Science University. The need for written consent was waived by the Institutional Review Board at Oregon Health \& Science University and deemed unnecessary. Welfare of Animals: This article does not contain any studies with animals performed by any of the authors.

\section{Consent for publication}


Not applicable.

\section{Availability of data and materials}

The datasets generated and/or analyzed during the current study are not publicly available due the small sample size and confidentiality concerns but are available from the corresponding author on reasonable request.

Competing Interests: From 2020-2021, Dr. Coronado has served as a scientific advisor for Exact Sciences and Guardant Health. All other authors declare they have no conflicts of interest.

Funding Sources: Research reported in this publication was supported by the National Cancer Institute of the National Institutes of Health under Award Number UG3CA244298. The content is solely the responsibility of the authors and does not necessarily represent the official views of the National Institutes of Health. Dr. Davis' time is supported in part by a career development award from the National Cancer Institute (1K07CA211971-01A1). The funder was not involved in the study design, collection, analysis, interpretation of data, the writing of this article or the decision to submit it for publication.

\section{Authors' contributions}

$\mathrm{JC}$ was the lead author of the paper, contributed to interpretation of analysis results, and drafted initial and subsequent drafts of the manuscript. EM prepared the qualitative analysis dataset and contributed to interpretation, including drafting sections of manuscript text. MP and JT supported data collection, data interpretation, and helped revise manuscript content. GC was the co-Prinicipal Investigator of the research team with $\mathrm{MD}$ and contributed to study conceptualization, acquiring financial support, expert knowledge of Boot Camp Translation approaches, the interpretation of study analysis and helped revise manuscript content. MD was the senior member of the research team and led study conceptualization, acquired financial support, and participated in all stages of the publication from data collection, study implementation, interpretation of study analysis and results and writing the article. All authors read and approved the final manuscript.

Acknowledgements: The authors express their gratitude to the members of the SMARTER CRC Advisory Board for sharing their experience and expertise and to the participants of the Boot Camp Translation sessions. We would also like to acknowledge the Advisory Board and to the community health centers (Lake Health Clinic, Lake County, Oregon, Pioneer Memorial Health Center, Heppner, Oregon, and Irrigon Medical Clinic, Irrigon, Oregon) for passing along the informational materials with people who might be interested in these activities, and for helping with the logistics of hosting a virtual event in rural areas.

This study was conducted as part of the NCl-funded consortium The Accelerating Colorectal Cancer Screening and Follow-up through Implementation Science (ACCSIS) Program. The overall aim of ACCSIS is to conduct multi-site, coordinated, transdisciplinary research to evaluate and improve colorectal cancer screening processes using implementation science strategies. 


\section{References}

1. Davidson KW, Barry MJ, Mangione CM, Cabana M, Caughey AB, Davis EM, et al. Screening for Colorectal Cancer: US Preventive Services Task Force Recommendation Statement. Jama. 2021;325(19):1965-77.

2. Henley SJ, Anderson RN, Thomas CC, Massetti GM, Peaker B, Richardson LC. Invasive Cancer Incidence, 2004-2013, and Deaths, 2006-2015, in Nonmetropolitan and Metropolitan Counties United States. MMWR Surveill Summ. 2017;66(14):1-13.

3. Davis MM, Renfro S, Pham R, Hassmiller Lich K, Shannon J, Coronado GD, et al. Geographic and population-level disparities in colorectal cancer testing: A multilevel analysis of Medicaid and commercial claims data. Prev Med. 2017;101:44-52.

4. Zahnd WE, James AS, Jenkins WD, Izadi SR, Fogleman AJ, Steward DE, et al. Rural-Urban Differences in Cancer Incidence and Trends in the United States. Cancer Epidemiol Biomarkers Prev. 2018;27(11):1265-74.

5. Blake KD, Moss JL, Gaysynsky A, Srinivasan S, Croyle RT. Making the Case for Investment in Rural Cancer Control: An Analysis of Rural Cancer Incidence, Mortality, and Funding Trends. Cancer Epidemiol Biomarkers Prev. 2017;26(7):992-7.

6. Wang H, Roy S, Kim J, Farazi PA, Siahpush M, Su D. Barriers of colorectal cancer screening in rural USA: a systematic review. Rural Remote Health. 2019;19(3):5181.

7. The Medicaid and CHIP Payment and Access Commission. MACStats: Medicaid and CHIP Data Book 2017 [Available from: https://www.macpac.gov/wp-content/uploads/2015/12/MACStatsMedicaid-CHIP-Data-Book-December-2017.pdf.

8. de Moor JS, Cohen RA, Shapiro JA, Nadel MR, Sabatino SA, Robin Yabroff K, et al. Colorectal cancer screening in the United States: Trends from 2008 to 2015 and variation by health insurance coverage. Prev Med. 2018;112:199-206.

9. Society AC. Colorectal Cancer Facts \& Figs. 2020-2022. Atlanta: American Cancer Society; 2020.

10. Fitzgerald TLL, C.S., Atluri PMB, J., Zervos EE. Insurance Payer Status and Race Explains Much of the Variability in Colorectal Cancer Survival. Journal of Cancer Therapy. 2014;5:1223-33.

11. Andrew AS, Parker S, Anderson JC, Rees JR, Robinson C, Riddle B, et al. Risk Factors for Diagnosis of Colorectal Cancer at a Late Stage: a Population-Based Study. J Gen Intern Med. 2018;33(12):21005.

12. Issaka RB, Avila P, Whitaker E, Bent S, Somsouk M. Population health interventions to improve colorectal cancer screening by fecal immunochemical tests: A systematic review. Prev Med. 2019;118:113-21.

13. Gupta S, Halm EA, Rockey DC, Hammons M, Koch M, Carter E, et al. Comparative effectiveness of fecal immunochemical test outreach, colonoscopy outreach, and usual care for boosting colorectal cancer screening among the underserved: a randomized clinical trial. JAMA Intern Med. 2013;173(18):1725-32. 
14. DeBourcy AC, Lichtenberger S, Felton S, Butterfield KT, Ahnen DJ, Denberg TD. Community-based preferences for stool cards versus colonoscopy in colorectal cancer screening. J Gen Intern Med. 2008;23(2):169-74.

15. Shokar NK, Vernon SW, Carlson CA. Validity of self-reported colorectal cancer test use in different racial/ethnic groups. Fam Pract. 2011;28(6):683-8.

16. Inadomi JM, Vijan S, Janz NK, Fagerlin A, Thomas JP, Lin YV, et al. Adherence to colorectal cancer screening: a randomized clinical trial of competing strategies. Arch Intern Med. 2012;172(7):575-82.

17. Gupta S, Coronado GD, Argenbright K, Brenner AT, Castañeda SF, Dominitz JA, et al. Mailed fecal immunochemical test outreach for colorectal cancer screening: Summary of a Centers for Disease Control and Prevention-sponsored Summit. CA Cancer J Clin. 2020;70(4):283-98.

18. Davis MM, Freeman M, Shannon J, Coronado GD, Stange KC, Guise JM, et al. A systematic review of clinic and community intervention to increase fecal testing for colorectal cancer in rural and lowincome populations in the United States - How, what and when? BMC Cancer. 2018;18(1):40.

19. Dubé C. Re-FIT-ting Colorectal Cancer Screening During and Beyond COVID. Gastroenterology. 2021;161(2):418-20.

20. Balzora S, Issaka RB, Anyane-Yeboa A, Gray DM, 2nd, May FP. Impact of COVID-19 on colorectal cancer disparities and the way forward. Gastrointest Endosc. 2020;92(4):946-50.

21. Coronado GD, Green BB, West, II, Schwartz MR, Coury JK, Vollmer WM, et al. Direct-to-member mailed colorectal cancer screening outreach for Medicaid and Medicare enrollees: Implementation and effectiveness outcomes from the BeneFIT study. Cancer. 2019;28(10):32567.

22. Administration HRS. Health Center Program Uniform Data System (UDS) Data Overview 2021 [Available from: https://data.hrsa.gov/tools/data-reporting/program-data.

23. Corley DA, Sedki M, Ritzwoller DP, Greenlee RT, Neslund-Dudas C, Rendle KA, et al. Cancer Screening During the Coronavirus Disease-2019 Pandemic: A Perspective From the National Cancer Institute's PROSPR Consortium. Gastroenterology. 2021;160(4):999-1002.

24. Norman N, Bennett C, Cowart S, Felzien M, Flores M, Flores R, et al. Boot camp translation: a method for building a community of solution. J Am Board Fam Med. 2013;26(3):254-63.

25. Thompson JH, Davis MM, Michaels L, Rivelli JS, Castillo ML, Younger BM, et al. Developing PatientRefined Messaging for a Mailed Colorectal Cancer Screening Program in a Latino-Based Community Health Center. J Am Board Fam Med. 2019;32(3):307-17.

26. Thompson JH, Davis MM, Leo MC, Schneider JL, Smith DH, Petrik AF, et al. Participatory Research to Advance Colon Cancer Prevention (PROMPT): Study protocol for a pragmatic trial. Contemp Clin Trials. 2018;67:11-5.

27. USDA. Rural-Urban Commuting Area Codes 2020 [Available from: https://www.ers.usda.gov/dataproducts/rural-urban-commuting-area-codes.aspx.

28. Health OOoR. Primary Care Service Areas: Rural and Frontier Definitions: Oregon Health \& Sciences University; 2020 [Available from: https://www.ohsu.edu/oregon-office-of-rural-health/orh-primarycare-service-areas. 
29. Nease DE, Jr., Simpson MJ, Zittleman L, Holtrop JS, Hall TL, Fisher M, et al. Making the Random the Usual: Appreciative Inquiry/Boot Camp Translation-Developing Community-Oriented Evidence That Matters. J Prim Care Community Health. 2020;11:2150132720904176.

30. Westfall JM, Zittleman L, Felzien M, Norman N, Tamez M, Backlund-Jarquin P, et al. Reinventing The Wheel Of Medical Evidence: How The Boot Camp Translation Process Is Making Gains. Health Aff (Millwood). 2016;35(4):613-8.

31. Hamilton AB, Brunner J, Cain C, Chuang E, Luger TM, Canelo I, et al. Engaging multilevel stakeholders in an implementation trial of evidence-based quality improvement in VA women's health primary care. Transl Behav Med. 2017;7(3):478-85.

32. Hamilton AB, Finley EP. Qualitative methods in implementation research: An introduction. Psychiatry Res. 2019;280:112516.

33. Honein-AbouHaidar GN, Kastner M, Vuong V, Perrier L, Daly C, Rabeneck L, et al. Systematic Review and Meta-study Synthesis of Qualitative Studies Evaluating Facilitators and Barriers to Participation in Colorectal Cancer Screening. Cancer Epidemiol Biomarkers Prev. 2016;25(6):907-17.

34. Kite J, Phongsavan P. Insights for conducting real-time focus groups online using a web conferencing service. F1000Res. 2017;6:122.

35. Han J, Torok M, Gale N, Wong QJ, Werner-Seidler A, Hetrick SE, et al. Use of Web Conferencing Technology for Conducting Online Focus Groups Among Young People With Lived Experience of Suicidal Thoughts: Mixed Methods Research. JMIR Ment Health. 2019;6(10):e14191.

36. Dos Santos Marques IC, Theiss LM, Johnson CY, McLin E, Ruf BA, Vickers SM, et al. Implementation of virtual focus groups for qualitative data collection in a global pandemic. Am J Surg. 2021;221(5):918-22.

\section{Figures}


- Met participant, assessed technology access, and conducted a demographic survey

\section{Hour Zoom Meeting (One week later)}

- Two CRC Expert Presentations, Facilitated Discussions, and reviewed existing Mailed FIT Materials

\section{Minute Follow-up Zoom Meeting (Two weeks later)}

- Made space for reflections, discussed Outreach Modes, and began tailoring the Mailed FIT Materials

\section{Minute Follow-up Zoom Meeting (Two weeks later)}

- Reviewed the tailored Mailed FIT Materials to ensure patient input was captured correctly

- Asked for patient input on Mailed FIT Call Scripts (Alerts \& Reminders)

1 Hour Final Zoom Meeting (Two weeks later)

- Shared final Mailed FIT Materials and Call Scripts, made space for reflections, and received final feedback

- Celebrated our accomplishments

\section{Figure 1}

\section{Boot Camp Translation COVID-19 Adapted Workflow}


Dear [PATIENT NAME],

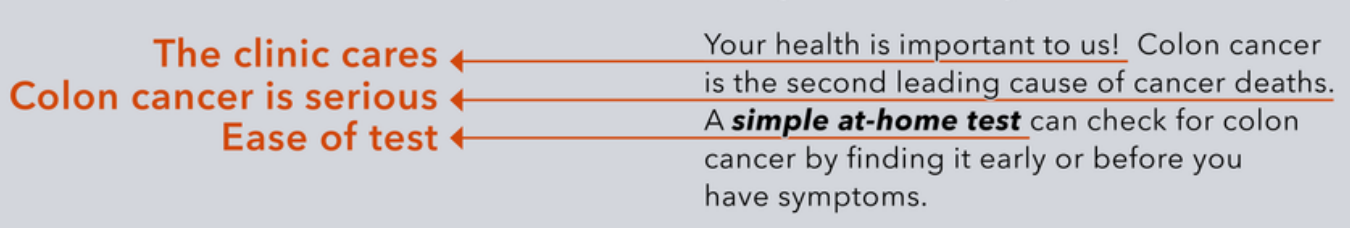

Keep an eye out

Everything you need to do this important for the FIT Kit test will be mailed to you. Here's what you should know about it:

- The test is easy, and you can do it safely in the privacy of your own home.

It is safe and private

Cost is important

- This test is completely FREE with your Medicaid (OHP) or Medicare insurance.

- Doing something so easy and safe could Pandemic proof save your life. NO clinic visit is needed for this test.

- Once you complete the test at home, you can drop it off at the clinic or mail it back in a pre-paid envelope.

- A member of your care team will call you

What happens next? with the test results.

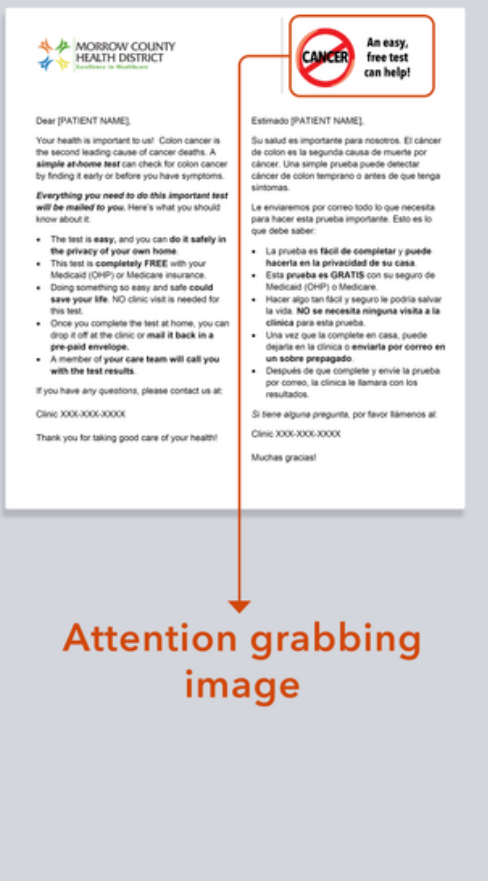

Appreciation for

If you have any questions, please contact us at: image

Clinic $X X X-X X X-X X X X$

being responsible

Thank you for taking good care of your health!

Figure 2

\section{Mailed FIT Outreach Letter Tailored for Rural Population}

